\title{
Local Mass and Heat Transfer on a Turbine Blade Tip
}

\author{
P. Jin and R. J. Goldstein \\ Heat Transfer Laboratory, Department of Mechanical Engineering, University of Minnesota, \\ Minneapolis, Minnesota, USA
}

Local mass and heat transfer measurements on a simulated high-pressure turbine blade-tip surface are conducted in a linear cascade with a nonmoving tip endwall, using a naphthalene sublimation technique. The effects of tip clearance $(0.86-6.90 \%$ of chord) are investigated at various exit Reynolds numbers $\left(4-7 \times 10^{5}\right)$ and turbulence intensities (0.2 and $12.0 \%)$.

The mass transfer on the tip surface is significant along its pressure edge at the smallest tip clearance. At the two largest tip clearances, the separation bubble on the tip surface can cover the whole width of the tip on the second half of the tip surface. The average mass-transfer rate is highest at a tip clearance of $1.72 \%$ of chord. The average mass-transfer rate on the tip surface is four and six times as high as on the suction and the pressure surface, respectively. A high mainstream turbulence level of $12.0 \%$ reduces average mass-transfer rates on the tip surface, while the higher mainstream Reynolds number generates higher local and average mass-transfer rates on the tip surface.

Keywords heat/mass transfer, linear cascade, naphthalene sublima-
tion technique, non-moving wall, tip clearance, turbine
blade

Tip leakage flow can have an important impact on the performance of a turbine system, in terms of both aerodynamic losses and thermodynamic penalty. The leakage flow induced by the pressure difference between the pressure side and the suction side of a blade increases the aerodynamic losses and decreases the efficiency in the turbine stage, reducing the turbine blade force and the work done in that stage. It has been estimated that

Received 21 December 2001; accepted 10 January 2002.

This research was supported by the U.S. Department of Energy, Federal Energy Technology Center through the AGTSR program.

Address correspondence to R. J. Goldstein, 125 Mechanical Engineering, 111 Church Street S.E., Minneapolis, MN 55455-0111, USA.E-mail: rjg@me.umn.edu a $1 \%$ clearance of blade height can cause a 1-2\% decrease in turbine stage efficiency (Booth et al., 1982). In addition, the tip leakage flow and its interaction with the main passage flow and secondary flows can increase heat transfer on the turbine blade surface near the tip, leading to high surface temperatures in regions near the blade tip, diminishing the structural durability of the blades (Mayle and Metzger, 1982).

Experimental studies have already been conducted to understand the tip leakage flow in turbine cascades, including flow visualization and measurement of static pressure and loss coefficients inside the tip clearance and blade passage in turbine cascades (Bindon, 1987; Kang and Hirsch, 1993; Moore and Tilton, 1988; Sjolander and Amrud, 1987; Yamamoto, 1988).

Though the effects of tip leakage flow on turbine blade heat transfer have been investigated, most studies have been conducted in idealized experimental conditions (on a flat plate or in rectangular cavities). Not many detailed local heat-transfer measurements on turbine blade tip surfaces and near-tip surfaces are available in the open literature.

The effect of leakage flow on turbine blade heat transfer was not emphasized until the paper of Mayle and Metzger (1982). Heat-transfer experiments were conducted on a flat surface with a moving wall provided by the rim surface of a rotating disk. Their results were in good agreement with the Colburn equation. Chyu and colleagues (1988) and Metzger and colleagues (1989) experimentally investigated mass and heat transfer in turbulent flow over shrouded rectangular cavities, using naphthalene sublimation technique and thermal surface coatings, respectively, to simulate the heat transfer at the tip region of grooved rotor blades.

The effects of sink flow (into the gap between tip and casing) on the blade pressure side, and of source flow on the blade suction side on turbine blade heat transfer were studied by Metzger and Rued (1989) and Rued and Metzger (1989) in a water tunnel. The heat-transfer measurements showed that the leakage generates large localized heat-transfer rates near the gap because of the strong acceleration in the sink flow. Even higher local heattransfer rates are found in the source flow, though a different mechanism - the presence of a small but intensive vortex at the gap edge - is involved. 
Metzger and colleagues (1991) proposed a simple model to describe the flow over an axial turbine blade tip and the adjacent stationary shroud using the Dittus-Boelter fully developed ductflow correlation together with an augmentation factor of 2.3 to account for the entry flow effect inside the tip. Film-cooled turbine blade-tip heat transfer and effectiveness were investigated by Kim and Metzger (1995) and Kim and colleagues (1995) on a simulated blade tip surface downstream of a single line of filmcooling injection sites using a transient thermal liquid crystal test.

More recently, Bunker and colleagues (1999) investigated the heat transfer and flow on the first-stage blade tip of a power generation gas turbine and provided full surface information on heat-transfer coefficients with pressure distribution on the blade tip and shroud for sharp-edge, radius-edge, and different clearances and freestream turbulence levels. The flow and heat transfer on the first-stage blade tip of an aircraft gas turbine was studied by Teng and colleagues (2000) and Azad and colleagues (2000) using a transient liquid crystal technique.

In this study, mass- and heat-transfer coefficients from a highpressure turbine blade tip in a linear cascade with tip clearance were measured by using a naphthalene sublimation technique. Use of heat and mass transfer provides information about the equivalent heat-transfer situation.

\section{MATERIALS AND METHODS}

The naphthalene sublimation technique is a well-established method that, with the mass- and heat-transfer analogy, makes it possible to obtain detailed data concerning the local transfer of mass and heat on complex surfaces. The naphthalene sublimation method and the heat and mass-transfer analogy were reviewed by Goldstein and Cho (1995). Goldstein and Spores (1988) used a local mass-transfer technique to obtain much greater detail about the convection process for the secondary flows in a turbine cascade. Goldstein and colleagues (1995) and Wang (1999) used naphthalene sublimation to investigate the effects of a high freestream turbulence level, length scale, and mainstream Reynolds number on convective transport from a turbine blade.

To summarize: the naphthalene sublimation technique can be used to determine the convective component of heat transfer with the absence of wall conduction and radiation errors. A masstransfer problem can be converted to a heat-transfer problem under the equivalent boundary conditions by using the massand heat-transfer analogy. Thus, the mass-transfer coefficient can be obtained from

$$
h_{m}=\frac{\dot{m}}{\rho_{v, w}-\rho_{v, \infty}}=\frac{\dot{m}}{\rho_{v, w}} \quad \text { since } \quad \rho_{v, \infty}=0
$$

and

$$
\dot{m}=\rho_{s} \frac{\delta y}{\delta \tau} .
$$

A dimensionless mass-transfer coefficient, the Sherwood number (Sh), which is similar to the heat-transfer Nusselt number, is often used for the comparison of results.

A multipurpose blowing type of wind tunnel in the Heat Transfer Laboratory at the University of Minnesota was employed in the study. Air drawn through a filter by a $22.4 \mathrm{~kW}$ blower arrived at the test section through a square contraction nozzle with an area ratio of 6.25 and an exit area of $45.7 \times$ $45.7 \mathrm{~cm}^{2}$.

The test section, as shown in Figure 1, was connected to the exit of the contraction of the wind tunnel. The linear turbine cascade consisted of five $45.7 \mathrm{~cm}$ high-pressure turbine rotor blades made of aluminum and having a central blade configuration. The top wall simulated the casing of the turbine, which was stationary relative to the blades in this study. The effects of a relative moving-tip endwall on the leakage flow has been found by some previous studies to be limited to a very thin endwall boundary and will be accounted for in future investigations. The space between the three middle blades and the tip endwall formed the blade tip clearance, which could be varied by adding aluminum spacers with varying thicknesses between the blades and the bottom wall. The tip clearances employed in this study were $0.86 \%, 1.72 \%, 3.45 \%$, and $6.90 \%$ of the chord length, $C$. The profile of the high-performance turbine blade and the geometry are shown in Figure 2a. The space between the bleeds and the outside blades as well as the orientation of the tailboards (see Figure 1) were adjustable so spatially periodic flows could be obtained in the blade passages. Balancing the cascade was achieved by comparing the static pressure obtained from a special pressure-measurement blade at the positions of the three middle blades with data from an inviscid flow solution. The established periodic flows in the blade passages are shown in Figure 2b.

A specially designed mold and modified casting procedures were employed to create a naphthalene blade with smooth naphthalene-covered surfaces, including the tip surface. To obtain a smooth naphthalene-cast profile, care had to be taken to control the temperature of the mold during casting. Previously calibrated T-type thermocouples were integrated with a GPIB card, enabling a Linux workstation to facilitate temperature measurements in the system, including the ambient temperature and the air-flow and naphthalene-surface temperatures. Pressures were measured by a pitot tube that was inserted at the incoming flow-measurement plane, as shown in Figure 1. The dynamic pressure and static pressure of the mainstream velocity were obtained by a micromanometer and a manometer, respectively. The depth change of the surfaces of the naphthalene blade during the test was measured by an automated four-axis data acquisition system developed in the Heat Transfer Laboratory at the University of Minnesota (Goldstein and Cho 1995).

The uncertainty in naphthalene surface temperature measurement was $0.09 \%$ in absolute temperature, with $95 \%$ confidence level. The uncertainty in mainstream velocity was $1.0 \%$; in the naphthalene sublimation depth measurement, it was $0.80 \%$, 


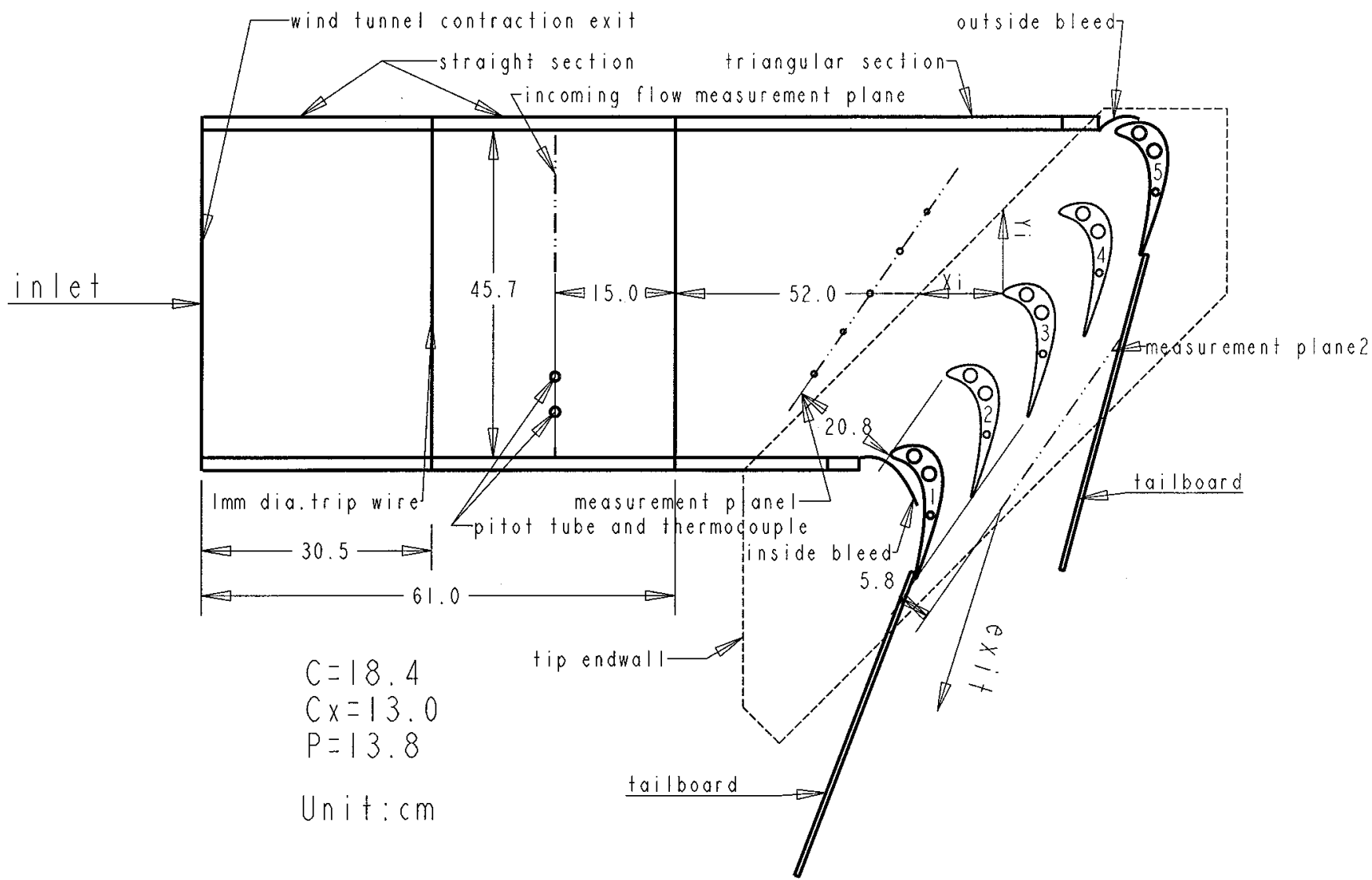

FIGURE 1

Planview of the test section.

which includes the error of repositioning the LVDT gauge. The uncertainties in the mass-transfer coefficient and the Sh, at 95\% confidence level, were $5.7 \%$ and $7.6 \%$, respectively. The errors were caused mainly by the uncertainty in the properties of naphthalene. The naphthalene loss due to natural convection was estimated and included in the above uncertainty analysis. The experimental system and procedures have been described in detail by Jin (2000).

The turbulent boundary layer characteristics established downstream of the trip wire were measured at three different locations on the measurement plane $1\left(X / C_{x}=-1.6\right.$ and see Figure 1) at a distance of a half pitch from each other on the tip endwall, using a single-sensor hot-wire probe. The integrated displacement thickness and shape factor were $1.7 \mathrm{~mm}$ and 1.38 , respectively; the displacement thickness was typical of that in a gas turbine engine ( $1 \%$ of chord). For a typical sublimation depth of $60 \mu \mathrm{m}$, the effect of a thinner naphthalene wall on the boundary layer thickness (of order of $10 \mathrm{~mm}$ ) can be neglected. The thickness of the naphthalene vapor boundary layer on the tip surface is considered thin relative to the smallest tip clearance because it has been found in previous studies that the leakage flow consists mainly of a inviscid core and a thin boundary layer on the tip, and the Schmidt number for the naphthalene vapor is larger than unity.

\section{RESULTS AND DISCUSSION}

The measurements were conducted in the blade chord coordinates $(x$ and $y$ ), as shown in Figure 3a. The dots in the figure are the positions at which the measurements took place, and they are aligned in lines parallel to the $y / C$ direction. In subsequent sections, the local distributions of the Sherwood number are presented in the blade chord coordinates, starting from the edge of the naphthalene surface $\left(y_{o}\right)$ along the pressure side of the blade. For contour plots, the blade chord coordinate was converted to the axial coordinates (X and $\mathrm{Y}$ ), as shown in Figure 3b. It is to be noted that the incoming flow to the cascade was at 35 degrees to the $\mathrm{X}$ direction and was roughly aligned with the dotted lines on the tip surface. However, the leakage flow in the tip clearance was complicated and may not have fallen along the dotted lines at which the mass-transfer coefficients were measured. Indeed, information from the measured mass transfer was analyzed to interpret the flow as well as mass and heat transfer on the tip surface.

\section{Effects of Tip Clearance}

To better understand the effects of tip clearance, static pressure measurements from a row of pressure taps that were $2.2 \mathrm{~cm}$ $(12 \% \mathrm{C})$ away from the blade tip are presented in Figure 4. The 


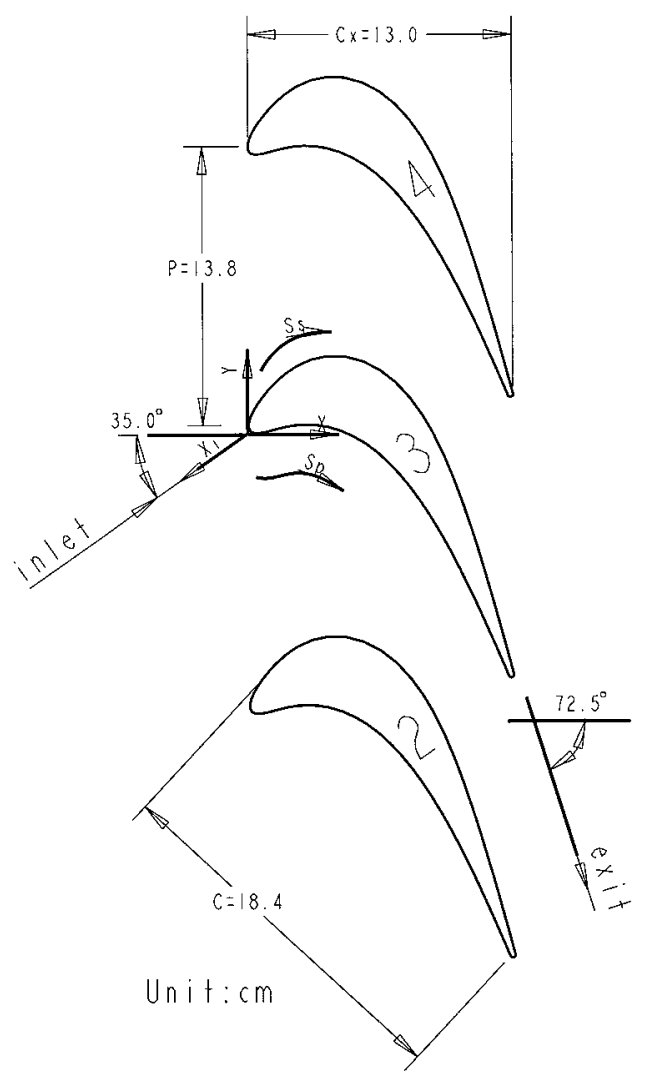

(a)

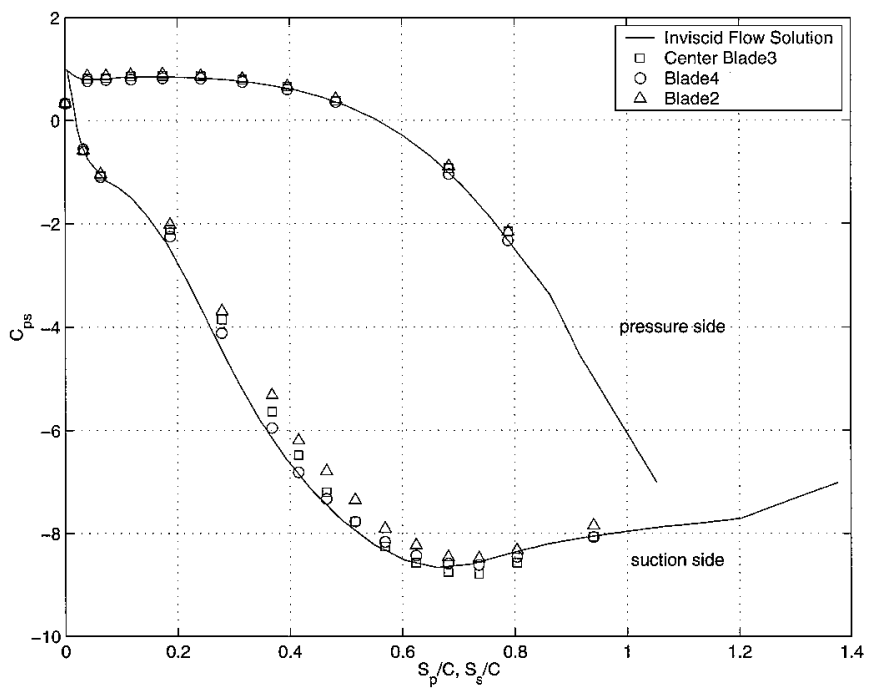

(b)

FIGURE 2

(a) Cascade blade geometry. (b) Cascade blade balance test data.

effects of secondary flows are the apparent cause for the difference between the data for zero tip clearance and those for midspan, especially close to the trailing edge. For measurements with tip clearances, the unloading effect (decrease in pressure

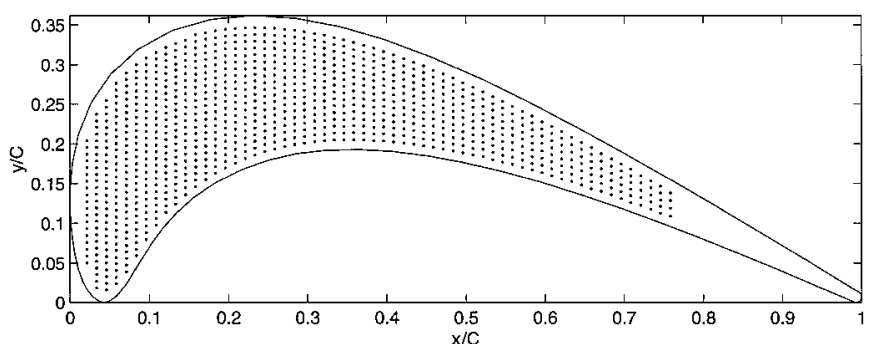

(a)

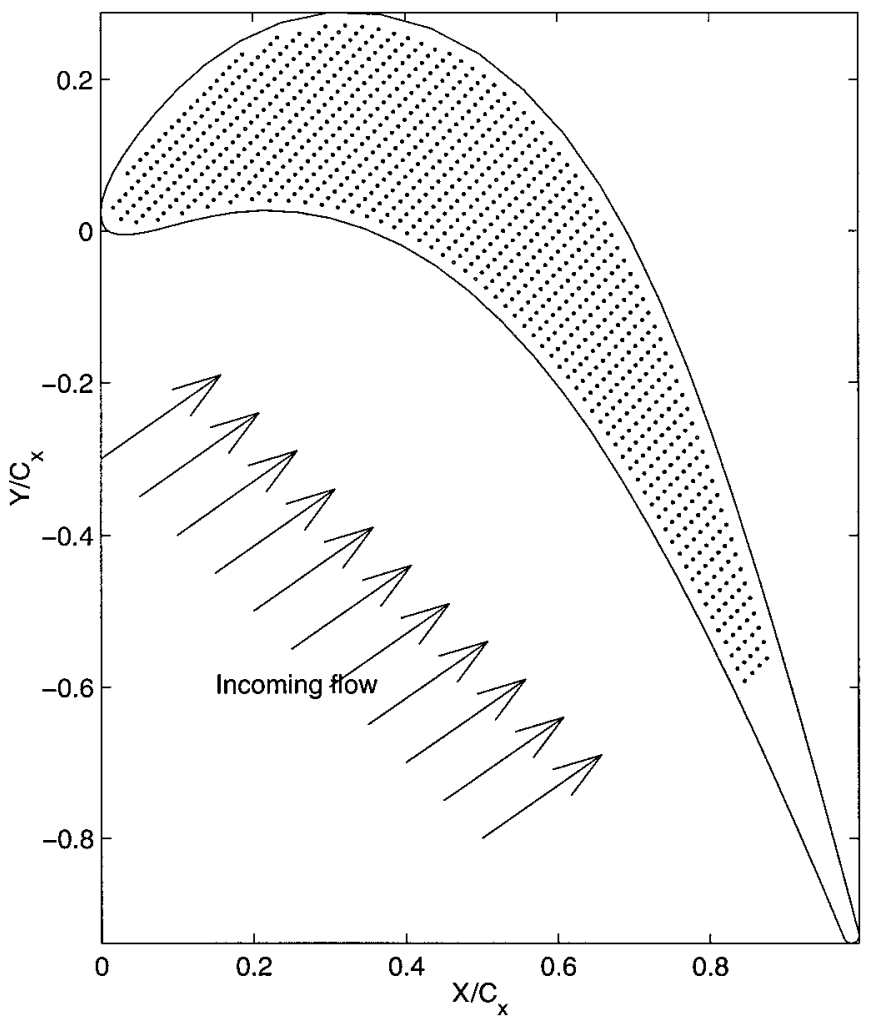

(b)

FIGURE 3

Tip surface coordinates. (a) Chord coordinate. (b) Axial coordinate.

difference) from the tip clearance can be clearly found in the plot. From the leading edge up to $S / C \approx 0.5$, the blade loading (i.e., the pressure difference) decreased with increase of tip clearance. In effect, very close to the leading edge $(S / C<0.05)$, the loading for the two largest tip clearances became negative, indicating that there may have been leakage flowing into (instead of out of) the tip clearance from the suction side. The loading decreased substantially for all the tip clearances in the second half of the blade, especially on the suction side, probably due to the presence of leakage vortex near the suction side of the tip.

The effects of tip clearance on the mass transfer on the tip surface are shown in the contour plots of Figure 5 at $\operatorname{Re}=5.8 \times 10^{5}$ and $\mathrm{Tu}=0.2 \%$. At a tip clearance $t / C=0.86 \%$, high masstransfer rates occurred very close to the pressure edge of the tip 


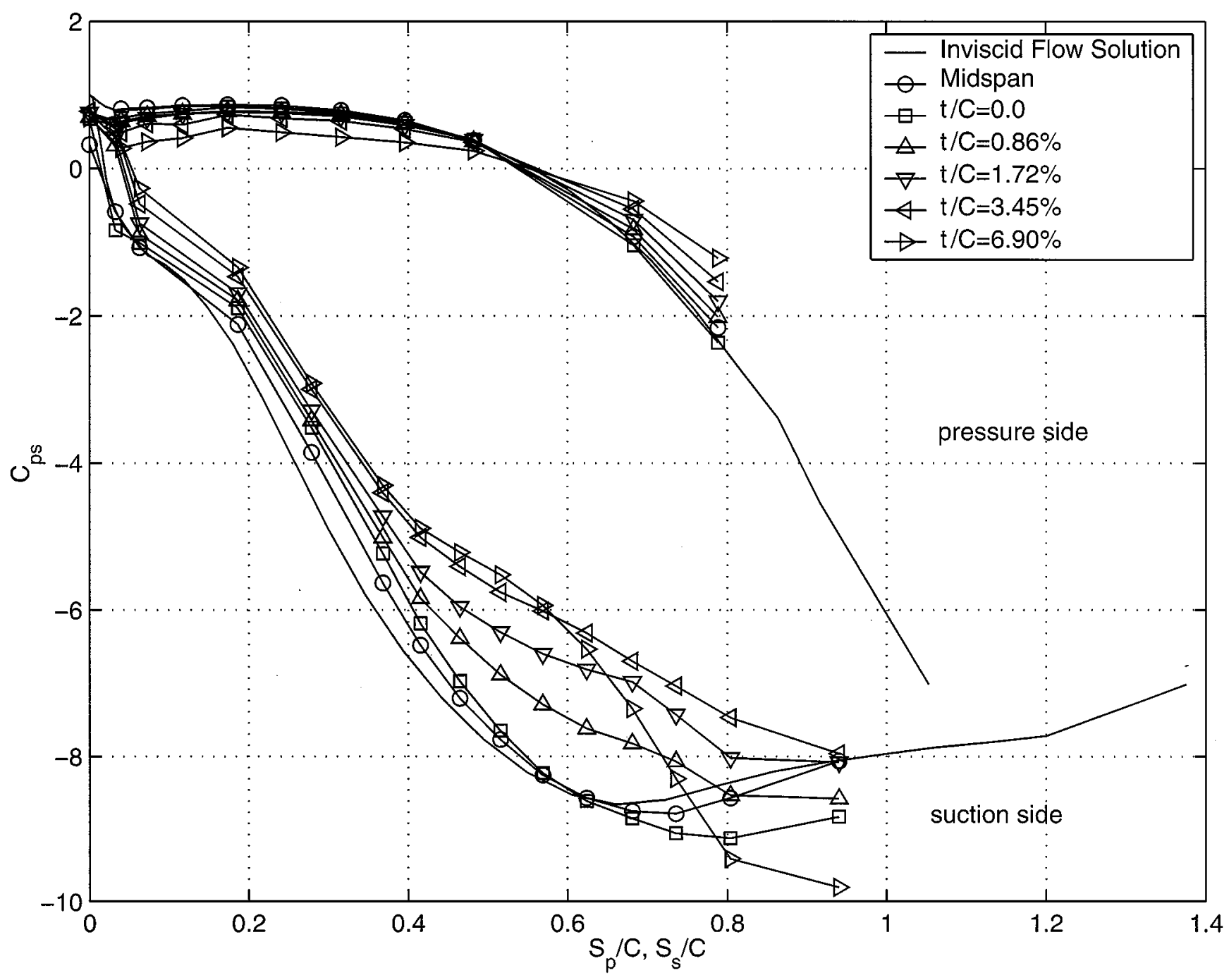

FIGURE 4

$C_{p s}$ near the blade tip for various tip clearances.

surface, especially around the mid-chord of the surface, where the Sh number descended from a value of 9500 at the pressure edge to about 3500 at the suction side. For a tip clearance of $1.72 \% C$, the high mass-transfer rates still existed near the pressure edge of the tip, with peak values a small distance from the pressure edge, particularly on the second half of the tip surface $\left(X / C_{x}>0.5\right)$. These peaks probably resulted from the reattachment of the leakage flow after a separation bubble near the pressure edge. A low mass-transfer zone appeared on the first half of the tip surface $\left(X / C_{x}<0.5\right)$ near the leading edge, which was perhaps caused by the relatively small leakage flow passing through that area. There were small peaks of high mass transfer on the first half of the tip and near the pressure edge, forming irregular mass-transfer patterns, which may indicate that the local leakage flow was not uniform.

At a higher tip clearance, $t / C=3.45 \%$, high mass-transfer peaks occurred near the pressure edge and moved farther away from the pressure side and the leading edge, while the low masstransfer region increased in size on the first half of the tip surface, probably because of the leakage flow coming from the suction side of the leading edge (Figure 5). For the largest tip clearance, $6.90 \% C$, the high mass transfer peaks appeared on the second half of the tip and close to the suction edge. At the mid-chord surface ( $\left.X / C_{x}=0.6\right)$, low mass-transfer is caused, perhaps, by the reverse flow occurring there. The low mass-transfer region affected by the leakage flow from the suction side of the leading edge became larger in size and extended to the second half of the tip surface at this highest tip clearance.

Local Sh versus $\left(y-y_{o}\right) / C$ at various $x / C$ locations are plotted in Figures 6 and 7 for differing tip clearances. For $t / C=$ $0.86 \%$, maximum mass-transfer rates always occurred at the start of the naphthalene surface $\left(y-y_{o}=0\right)$, very close to the pressure-side edge for all $x / C$ locations, showing that the leakage flow separated and reattached on the tip surface immediately 


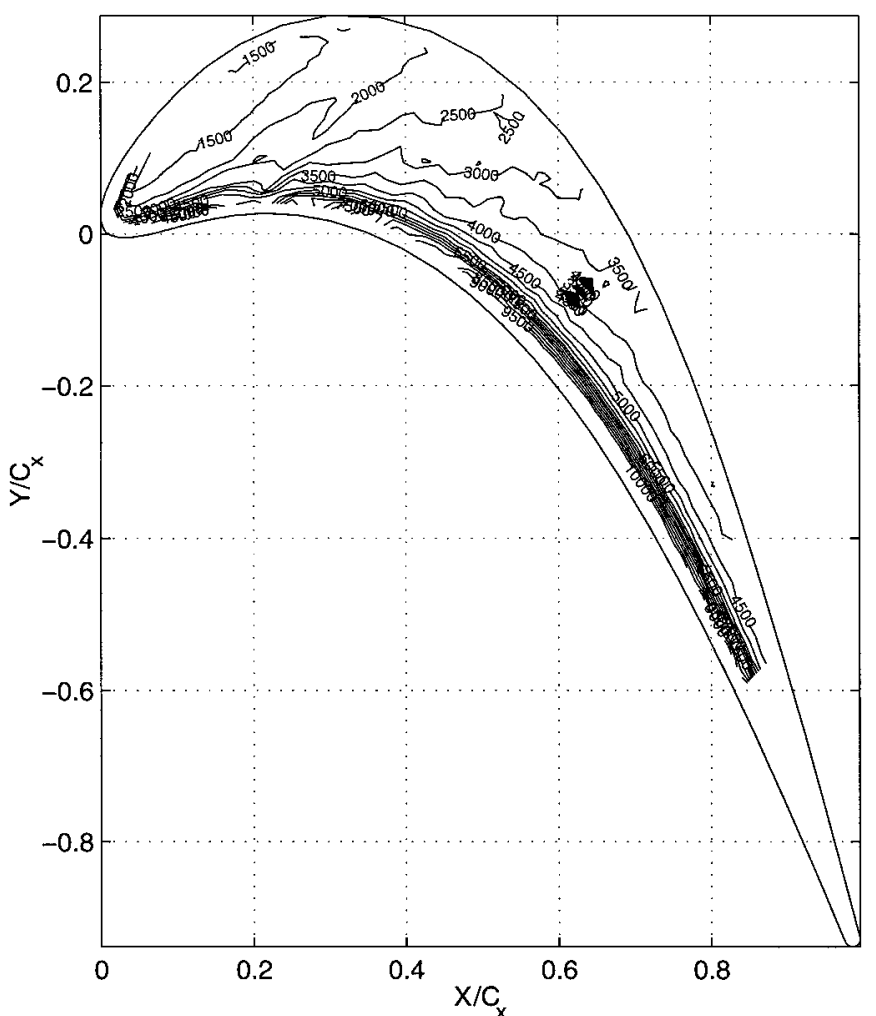

(a)

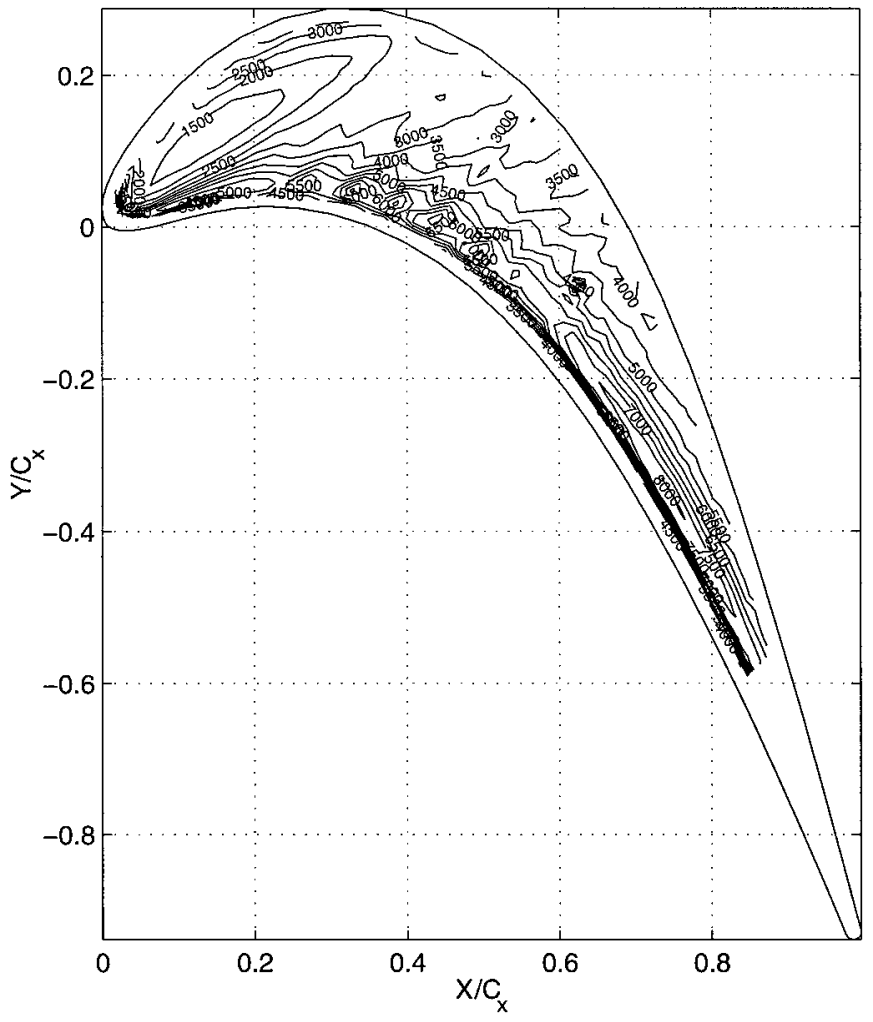

(b)

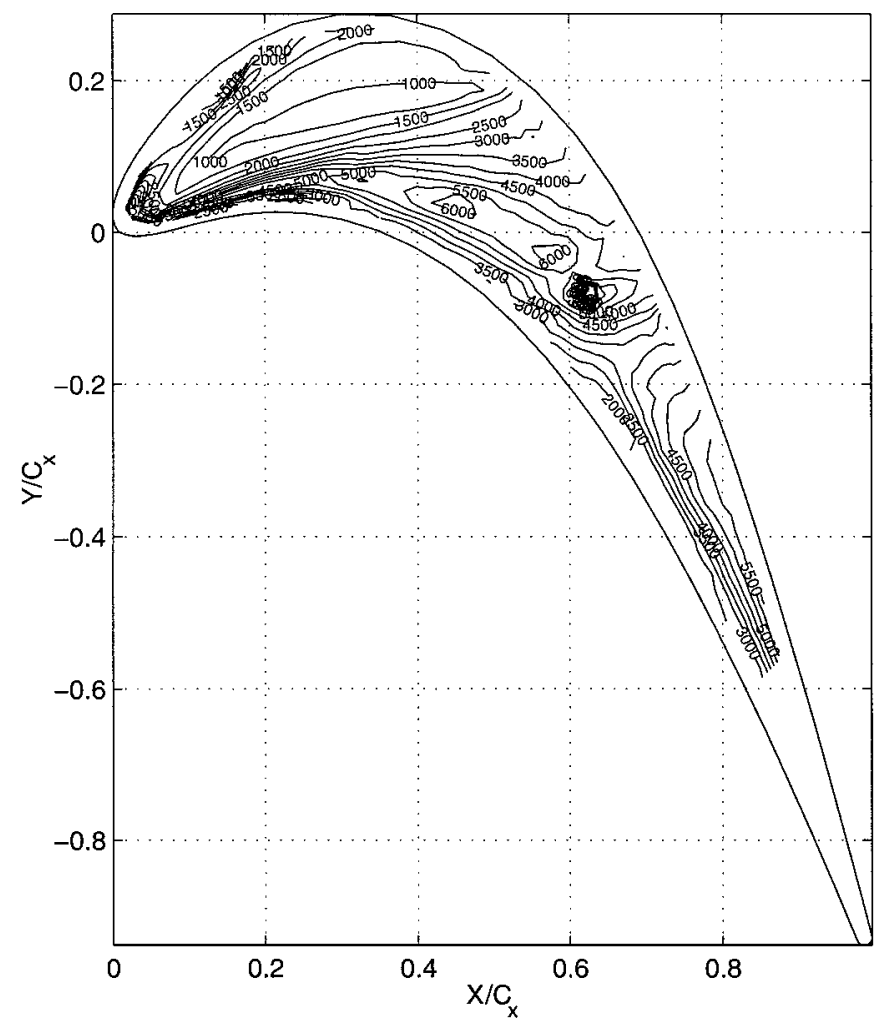

(c)

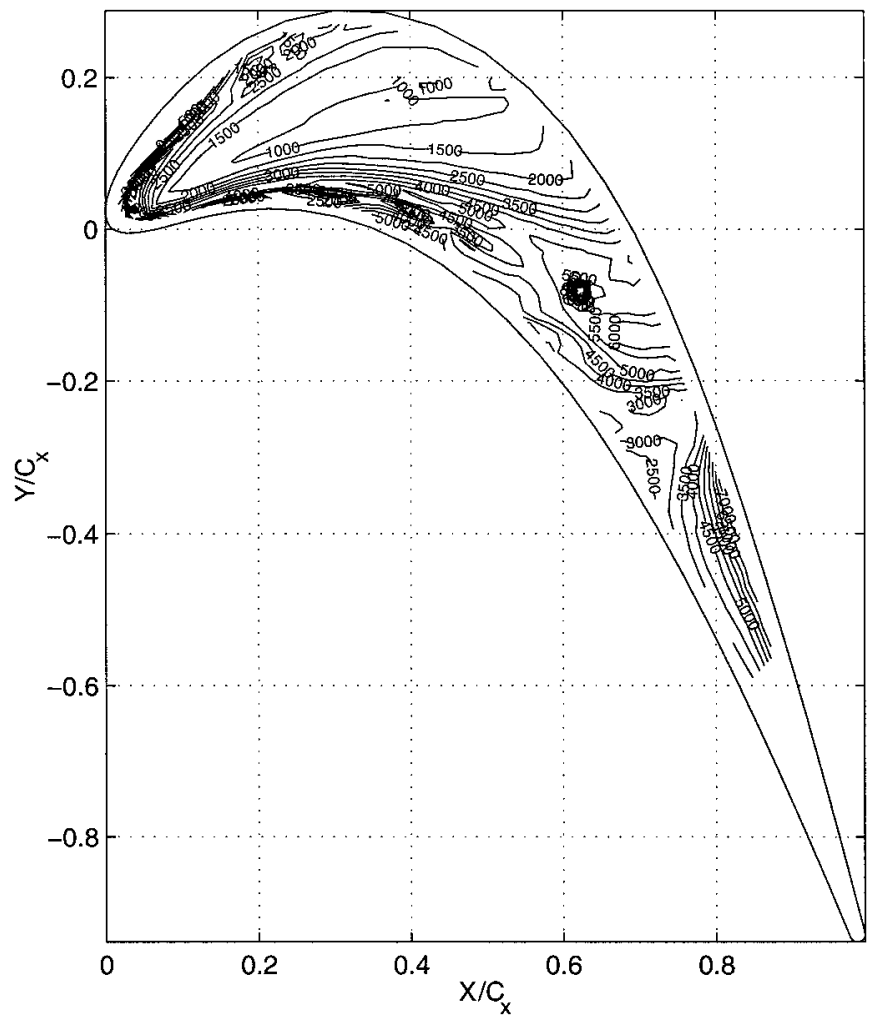

(d)

FIGURE 5

Sh contour on the tip surface. (a) $t / C=0.86 \%$. (b) $t / C=1.72 \%$. (c) $t / C=3.45 \%$. (d) $t / C=6.90 \%$. 

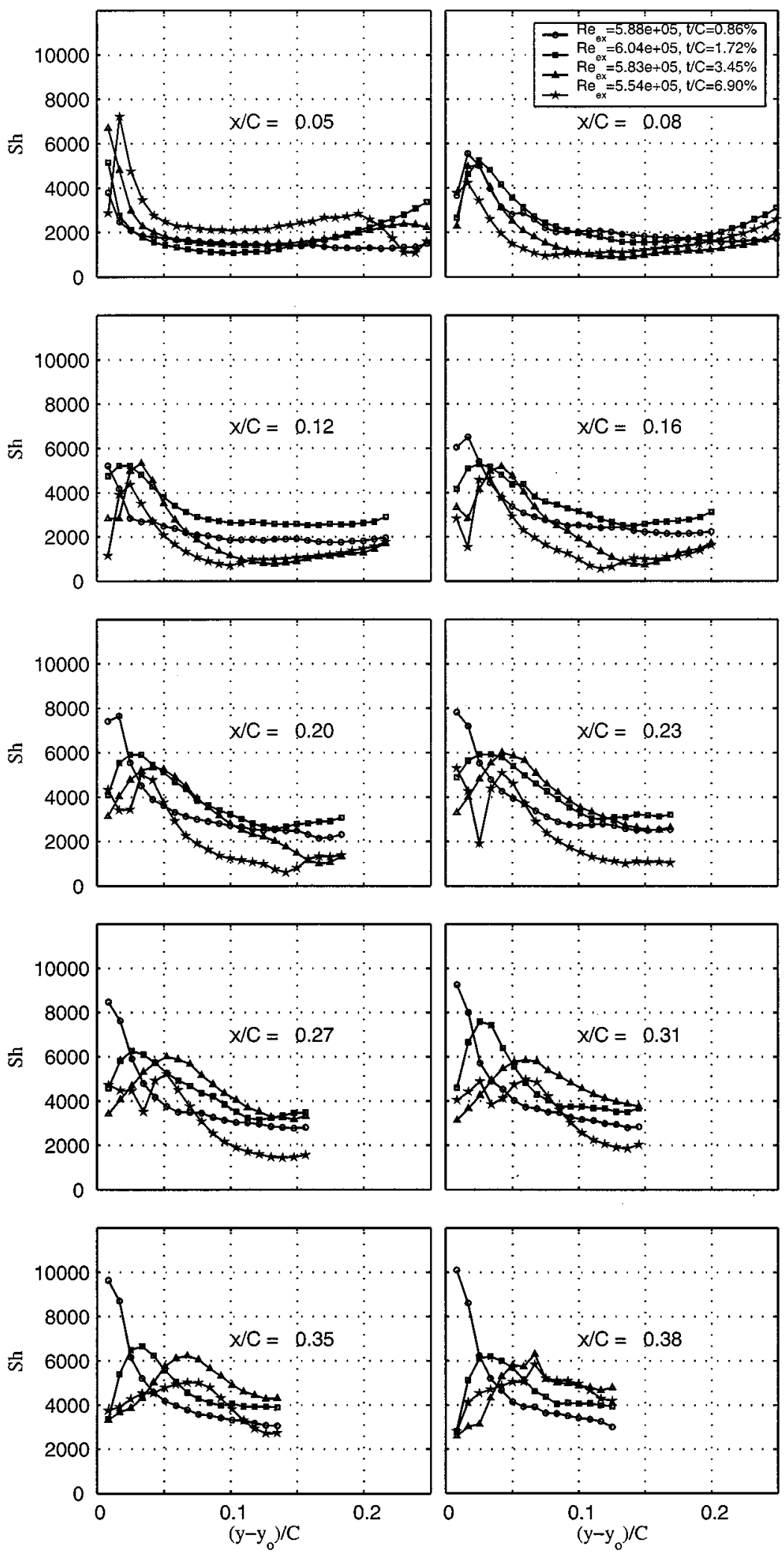

FIGURE 6

Local Sh on the tip surface at various clearances. 

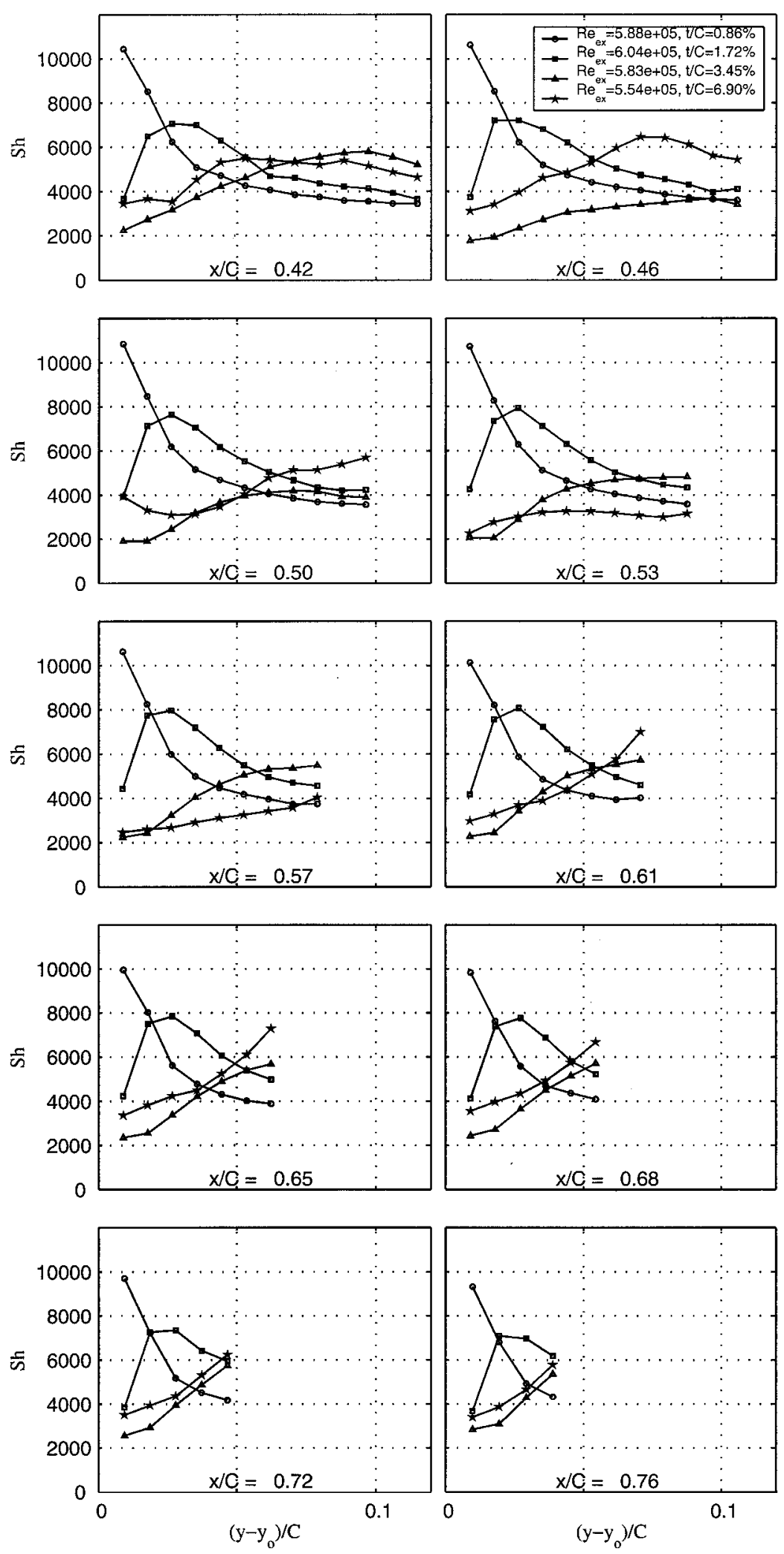

FIGURE 7

Local Sh on the tip surface at various clearances (continuing from Figure 6). 

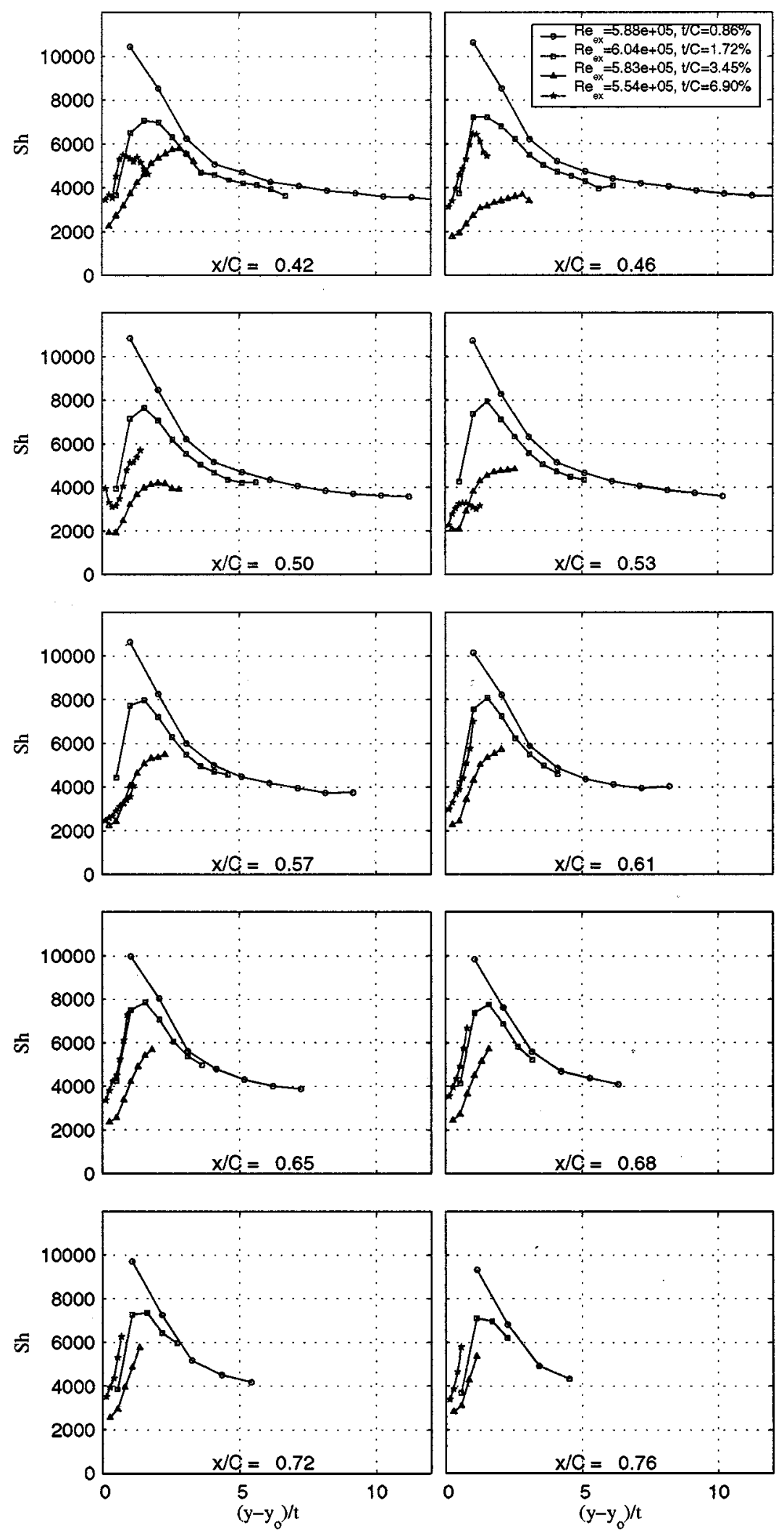

FIGURE 8

Local Sh on the tip surface versus $\left(y-y_{o}\right) / t$. 
at the pressure-side edge of the tip or did not separate at all. At tip clearance of $1.72 \% C$, mass-transfer peaks existed at a small distance $\left(\left(y-y_{o}\right) \approx 0.02 C\right)$ from the start of the naphthalene surface for all $x / C$ locations, perhaps indicating that the leakage flow reattached over a separation bubble close to the pressure-side edge of the tip. For the two largest tip clearances, the peaks of the mass-transfer Sh move farther away from the pressure edge and toward the suction side, upstream of $x / C=0.46$, showing perhaps a larger separation bubble on the first half of the tip surface. The reason the lowest Sh occurred around $\left(y-y_{o}\right)=0.03 C$ from $x / C=0.16$ to $x / C=0.31$ for the largest tip clearance was not clear. After $x / C=0.46$, the separation bubble was perhaps large enough to cover the whole tip, with peaks of mass transfer near the suction edge of the tip.

The same local Sh at different $x / C$ locations are plotted in Figure 8 against $\left(y-y_{o}\right) / t$, at various tip clearances. For $x / C>0.42$, the peaks of the local mass transfer occur at about
$2 t$ for almost all $x / C$ locations and at all clearances, indicating the similarity of the leakage flow.

In summary: for the smallest tip clearance of $0.86 \% C$, the entrance flow effect of the leakage flow on the mass transfer is quite clear, with the maximum at the leakage flow entrance being three to four times as high as that farther downstream. For larger tip clearances, this entrance flow effect was also evident, but weaker. For the two largest tip clearances, the separation bubble was so big in the second half of the tip surface that it covered the whole tip.

The Sh averaged in $y$ direction versus $x / C$ is plotted in Figure 9. The averaged mass transfer rate for $t / C=1.72 \%$ was higher than that for $t / C=0.86 \%$. A similar result was obtained by Teng and colleagues (2000) and Azad and colleagues (2000) and can be explained by the combined effects of the shear flow and total leakage flow rate inside the tip clearance. For the two largest tip clearance, the first peak near the leading edge $(x / C=0)$ was

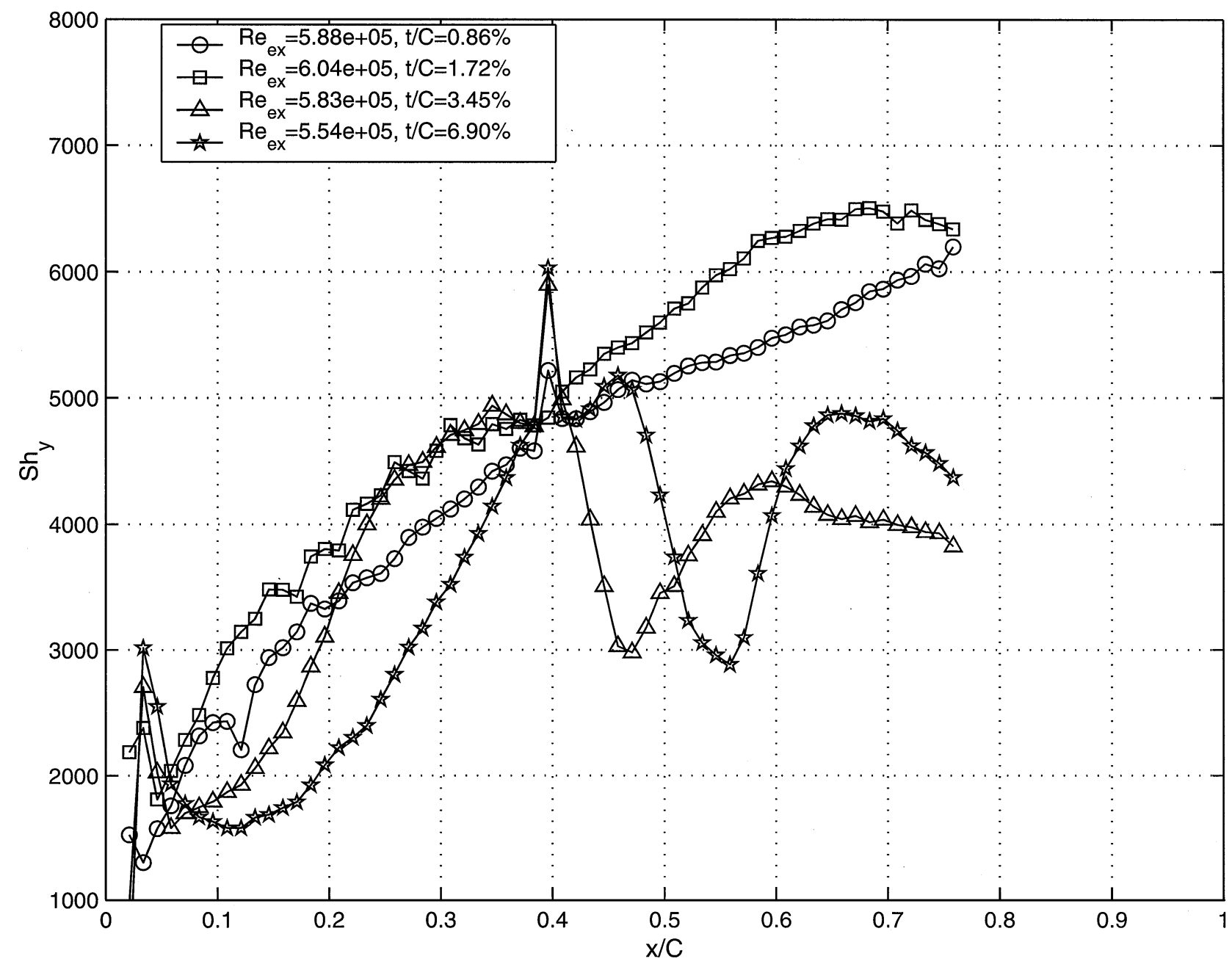

FIGURE 9

Average Sh on the tip surface. 
TABLE 1

Surface-Averaged Sh at Various Tip Clearances

\begin{tabular}{lccccr}
\hline$t / C(\%)$ & 0.00 & 0.86 & 1.72 & 3.45 & 6.90 \\
Pressure & 645.4 & 662.1 & 727.4 & 746.7 & 828.3 \\
Suction & 1067.1 & 1169.1 & 1120.1 & 1036.4 & 764.2 \\
Tip surface & - & 4341.3 & 4835.5 & 3673.7 & 3526.5 \\
\hline
\end{tabular}

perhaps due to the high mass transfer on the suction edge of the leading edge, where leakage entered from the suction side at the high tip clearances, while the valleys around $x / C=0.5$ were caused by the separation and reverse flow. The localized peak around $x / C=0.4$ for all cases was an artifact caused by measurement error near the injection hole of the naphthalene casting.

To obtain an overall sense of those effects, the surfaceaveraged mass-transfer Sh is presented in Table 1. The mass transfer, Sh, on the pressure and the suction surfaces, based on Jin (2000), are averaged over the length of the blade chord, starting from the tip. In Table 1, it can be seen that surfaceaveraged mass transfer, Sh, was about four and six times as high on the tip surface as on the suction and the pressure surfaces, respectively. The tip surface-averaged $\mathrm{Sh}$ is also comparable to the $\mathrm{Nu}$ numbers calculated from the literature, as listed in Table 2 .

\section{Effects of Mainstream Re Number and Turbulence}

At a given tip clearance, $t / C=0.86 \%$, the effects of mainstream $\mathrm{Re}$ and $\mathrm{Tu}$ were investigated. The local mass transfer $\mathrm{Sh} / \mathrm{Re}_{t}^{0.8}$ at different $x / C$ locations is shown in Figures 10 and 11 in terms of $\left(y-y_{o}\right) / t$. The entrance flow characteristics were clear at this smallest tip clearance for all $\mathrm{Re}$ and $\mathrm{Tu}$ cases. The figures show that the mass transfer Sh generally increases with an increasing mainstream Reynolds number, while the high mainstream turbulence intensity leads to lower mass transfer rates compared to those of lower turbulence levels at a similar Reynolds number for $x / C>0.27$. At a low mainstream Reynolds number $\left(\operatorname{Re}_{e x}=4.65 \times 10^{5}\right)$ or a high mainstream turbulence level $(\mathrm{Tu}=12 \%)$, the separation bubble occurring close to the pressure edge of the tip is apparently larger and the peaks

TABLE 2

Surface-Averaged $\mathrm{Nu}$ at the Tip

\begin{tabular}{lccc}
\hline$t / C(\%)$ & $0.85(1.27 \mathrm{~mm})$ & $1.3(2.03 \mathrm{~mm})$ & $1.8(2.79 \mathrm{~mm})$ \\
$\begin{array}{c}\text { Heat-transfer } \\
\text { coefficient } \\
\left(W / m^{2} K\right)\end{array}$ & 875 & 975 & 1050 \\
$\mathrm{Nu}$ & & & \\
\hline
\end{tabular}

$\mathrm{Re}_{e x}=2.57 \times 10^{6} ; \mathrm{Tu}=9 \% ; \mathrm{C}=14.9 \mathrm{~cm}$.

Note: Data are from Bunker and colleagues (1999). of mass transfer occur at a small distance downstream of the start of the naphthalene surface on the tip. The data collapse to one curve after $\left(y-y_{o}\right)=5$ for all cases with different Reynolds numbers at almost all $x / C$ locations, which suggests that though the leakage flow may have a laminar separation due to the large acceleration rate at the inlet of the clearance, the leakage flow after reattachment is turbulent inside the small tip clearance of $(0.86 \% C)$.

Averaged Sh along $x / C$ for varying Reynolds numbers and turbulence levels are shown in Figure 12. As stated earlier, the higher the mainstream Reynolds number, the higher the average mass transfer rates on the tip surface. The high mainstream turbulence intensity suppresses the mass transfer rate on the tip surface compared with the lower turbulence level at a similar mainstream exit Reynolds number.

\section{CONCLUSIONS}

In this study, local mass-transfer measurements from a simulated high-pressure turbine blade-tip surface were performed using the naphthalene sublimation technique. The experiments were conducted in a linear cascade consisting of five highpressure blades with tip clearances. There was no relative movement between the tip endwall and the blade tip. The Reynolds number was similar to that in a gas turbine engine environment $\left(\delta_{1} / C=0.01\right)$, with an exit Reynolds number of about $5.8 \times 10^{5}$. The effects of tip clearance, the mainstream Reynolds number, and the turbulence intensity were investigated. The following conclusions can be drawn from the study:

1. The entrance flow effect induces mass-transfer rates three to four times larger than those along the pressure edge of the tip surface at the smallest tip clearance of $0.86 \% C$. It was also found that the leakage flow after reattachment was turbulent.

2. As the tip clearance increased the peaks of the mass transfer moved away from the pressure edge due to the larger separation bubble near the pressure edge. At the two largest tip clearances, the separation bubble could cover the whole width of the tip on the second half of the tip surface $(X / C>0.5)$.

3. A low mass-transfer region on the first half of the tip was caused by a low leakage flow rate at small tip clearances, while at large tip clearances, the similar low mass-transfer region was induced by leakage flow from the suction side.

4. The average mass transfer rate is highest at a tip clearance of $1.72 \% C$. The averaged mass-transfer rate on the tip surface was four and six times higher than on the suction and the pressure surfaces, respectively.

5. A high mainstream turbulence level of $12.0 \%$ reduces average mass-transfer rates somewhat on the tip surfaces, while a higher mainstream Reynolds number causes higher local and average mass-transfer rates on the tip surfaces. 

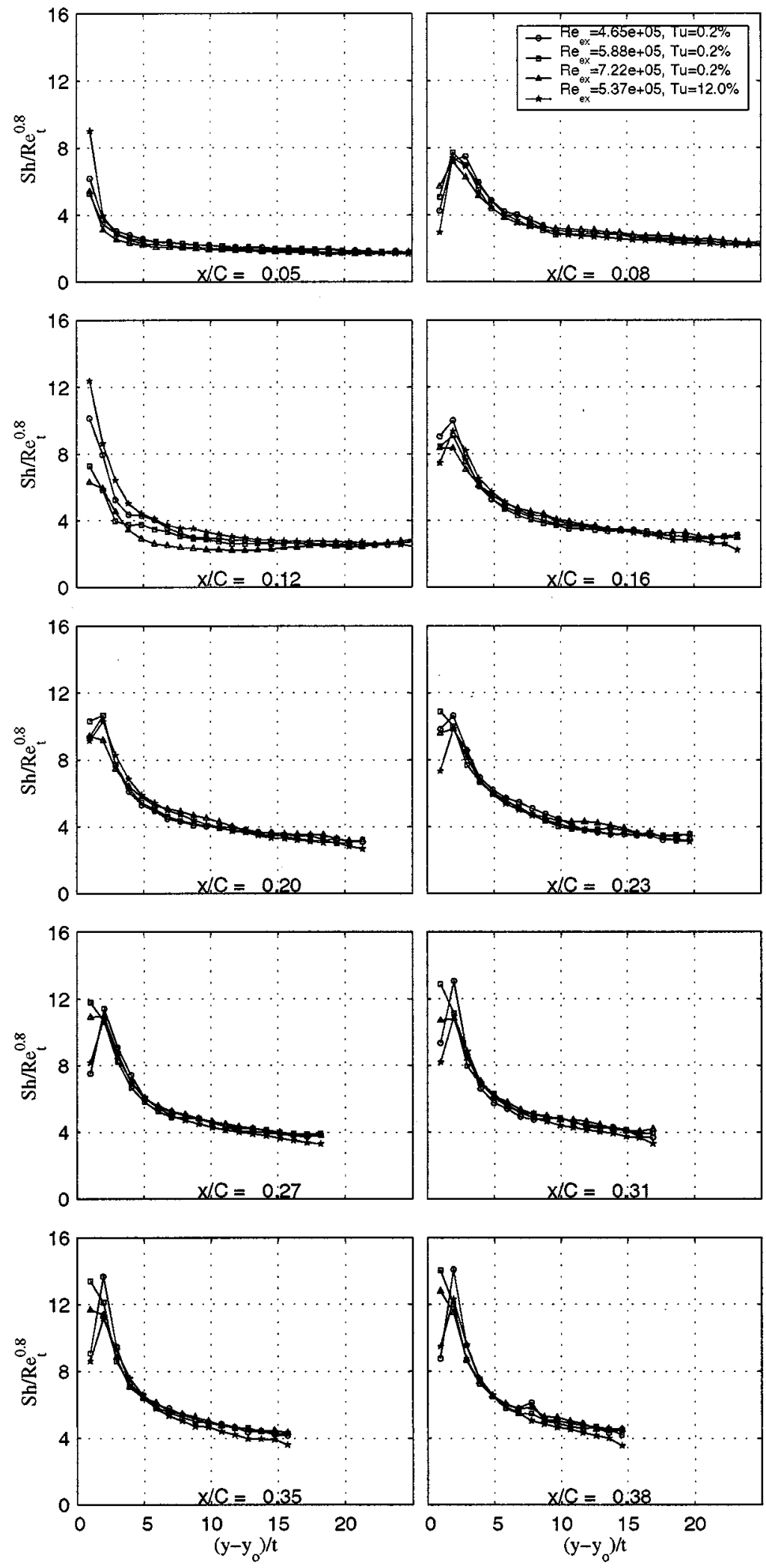

FIGURE 10

Local Sh $/ \operatorname{Re}_{t}^{0.8}$ on the tip surface at $t / C=0.86 \%$. 

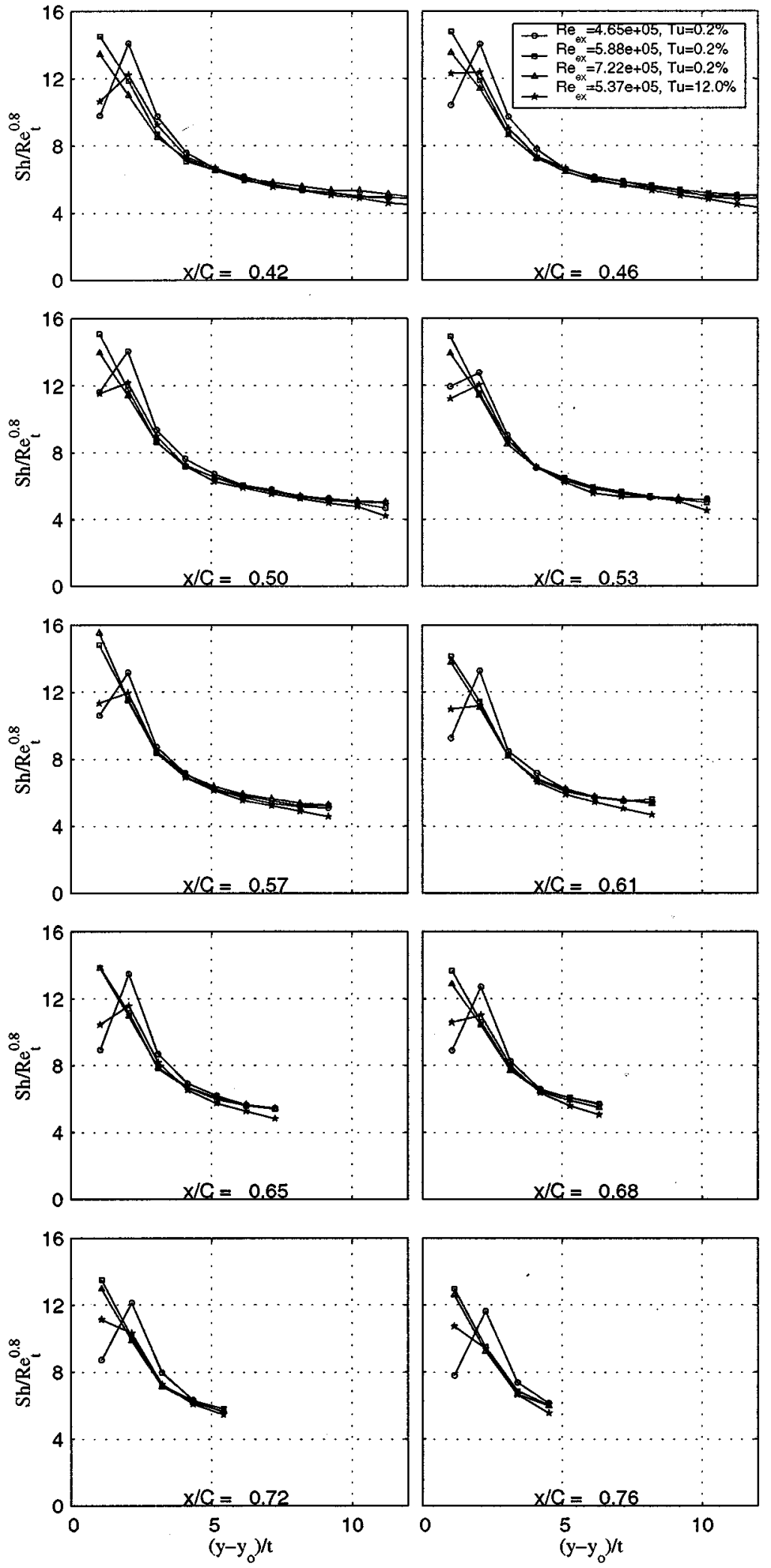

FIGURE 11

Local Sh $/ \operatorname{Re}_{t}^{0.8}$ on the tip surface at $t / C=0.86 \%$. 


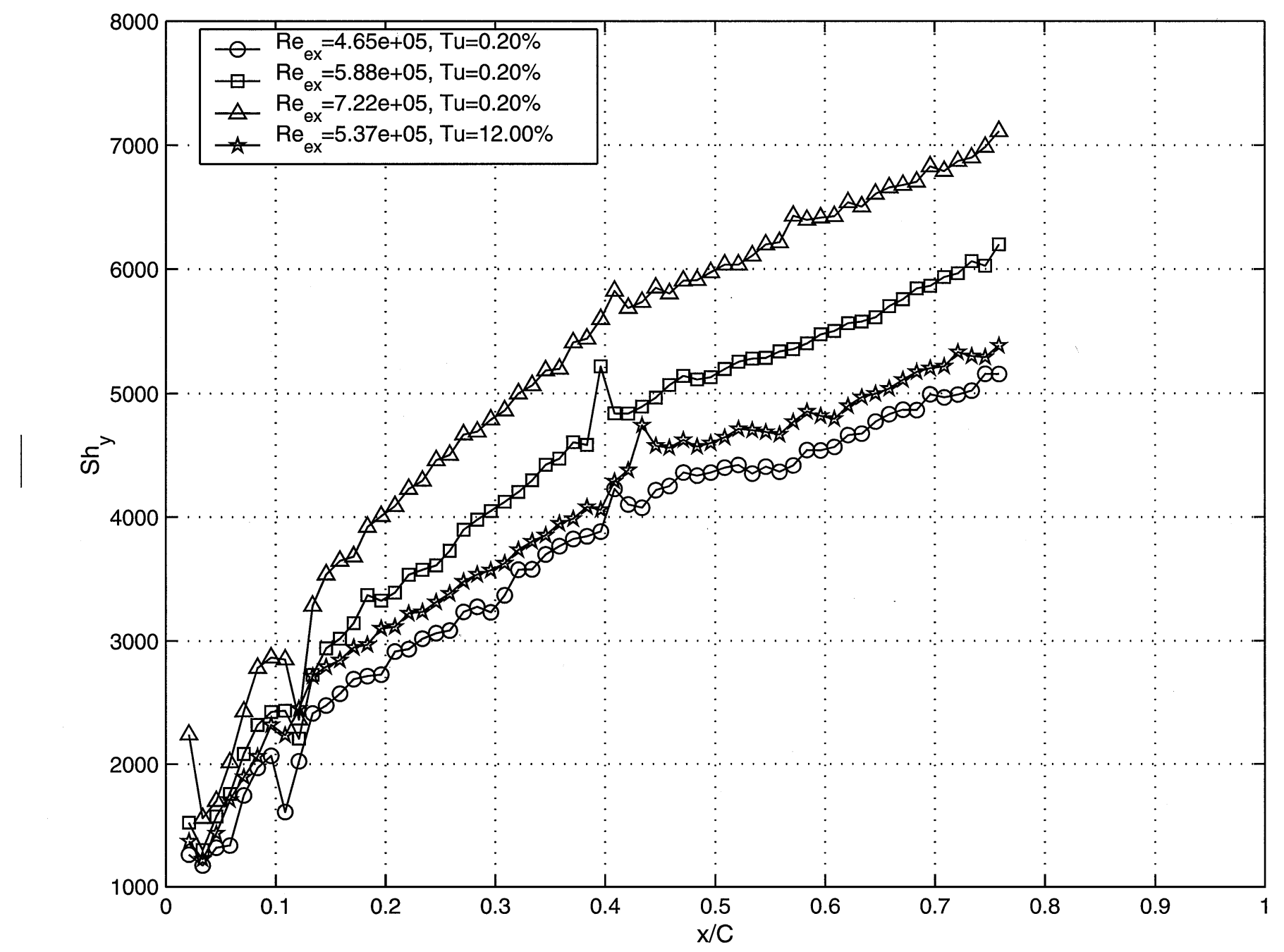

FIGURE 12

Average Sh on the tip surface at $t / C=0.86 \%$.

\section{NOMENCLATURE}

$C \quad$ Chord of blade $=18.4 \mathrm{~cm}$ in this study

$C_{x} \quad$ Axial chord of blade $=13.0 \mathrm{~cm}$ in this study

$C_{p s} \quad$ Static-pressure coefficient with respect to reference static pressure $p_{o}=\left(p-p_{o}\right) / 0.5 \rho V^{2}$

$D_{n a p h} \quad$ Naphthalene vapor diffusivity in air

$H \quad$ Height (span) of blade

$h_{m} \quad$ Mass-transfer coefficient

$\dot{m} \quad$ Mass flux

$P \quad$ Pitch of blade $=13.8 \mathrm{~cm}$ in this study

$\mathrm{Re}_{e x} \quad$ Exit Reynolds number based on chord and exit velocity

$\operatorname{Re}_{t} \quad$ Reynolds number based on $2 t$ and $V$

$S_{p} \quad$ Curvilinear coordinate along the pressure surface

$S_{s} \quad$ Curvilinear coordinate along the suction surface

Sh Mass-transfer Sherwood number $=h_{m} C / D_{\text {naph }}$

$\overline{\mathrm{Sh}_{y}} \quad$ Sherwood number averaged in $y$ direction

$t \quad$ Blade tip clearance
$\mathrm{Tu} \quad$ Inlet turbulence intensity

$V \quad$ Mainstream velocity

$X \quad$ Axial direction of the cascade

$x \quad$ Blade chord direction

$Y \quad$ Pitchwise direction of the cascade

$y \quad$ Traverse to the blade chord direction

$y_{o} \quad$ Start of naphthalene surface in y coordinate

\section{Greek Symbols}

$\delta \tau \quad$ Net time duration in the wind tunnel

$\delta_{1} \quad$ Boundary layer displacement thickness

Sy Net naphthalene layer depth change due to turbulent convection

$\rho_{s} \quad$ Solid naphthalene density

$\rho_{v, \infty} \quad$ Naphthalene vapor density in mainstream

$\rho_{v, w} \quad$ Naphthalene vapor density at wall 


\section{REFERENCES}

Azad, G. S., Han, J.-C., Teng, S., and Boyle, R. J. 2000. Heat transfer and pressure distribution on a gas turbine blade tip. ASME paper 2000-GT-194.—: American Society of Mechanical Engineers.

Bindon, J. P. 1987. Pressure distributions in the tip clearance region of an unshrouded axial turbine as affecting the problem of tip burnout. ASME paper 87-GT-230.-: American Society of Mechanical Engineers.

Booth, T. C., Dodge, P. R., and Hepworth, H. K. 1982. Rotor-tip leakage. i. basic methodology. ASME Journal of Engineering for Gas Turbines and Power 104:154-161.

Bunker, R. S., Baily, J. C., and Ameri, A. A. 1999. Heat transfer and flow on the first stage blade tip of a power generation gas turbine. 1 . Experimental results. ASME paper 99-GT-169.—: American Society of Mechanical Engineers.

Chyu, M. K., Moon, H. K., and Metzger, D. E. 1988. Heat transfer in the tip region of grooved turbine blades. ASME paper 88-GT-213.—: American Society of Mechanical Engineers.

Goldstein, R. J., and Cho, H. H. 1995. A review of mass transfer measurements using naphthalene sublimation. Experimental Thermal and Fluid Science 8:416-434.

Goldstein, R. J., and Spores, R. A. 1988. Turbulent transport on the endwall in the region between adjacent turbine blades. ASME Journal of Heat Transfer 110:862-869.

Goldstein, R. J., Wang, H P., and Jabbari, M. Y. 1995. Influence of secondary flows near the endwall and boundary layer disturbance on convective transport from a turbine blade. ASME Journal of Turbomachinery 117:657-665.

Jin, P. 2000. Local Measurement and Numerical Modeling of Mass/Heat Transfer from a Turbine Blade in a Linear Cascade with Tip Clearance. (Ph.D. diss., University of Minnesota).

Kang, S., and Hirsch, C. 1993. Experimental study on the three-dimensional flow within a compressor cascade with tip clearance. 1. Velocity and pressure fields. ASME Journal of Turbomachinery 115:435-443.

Kim, Y. W., Downs, J. P., Soechting, F. O., Abdel-Messeh, W., Steuber, G. D., and Tanrikut, S. 1995. Summary of the cooled turbine blade tip heat transfer and film effectiveness investigations performed by Dr. D. E. Metzger. ASME Journal of Turbomachinery 117:1-11.

Kim, Y. W., and Metzger, D. E. 1995. Heat transfer and effectiveness on film-cooled turbine blade tip models. ASME Journal of Turbomachinery 117:12-21.

Mayle, R. E., and Metzger, D. E. Heat transfer at the tip of an unshrouded turbine blade. 87-92. Proceedings of 7th International Heat Transfer Conference, vol. 3.

Metzger, D. E., Bunker, R. S., and Chyu M. K. 1989. Cavity heat transfer on a transverse grooved wall in a narrow flow channel. ASME Journal of Heat Transfer 111:73-79.

Metzger, D. E., Dunn, M. G., and Hah, C. 1991. Turbine tip and shroud heat transfer. ASME Journal of Turbomachinery 113:502507.

Metzger, D. E., and Rued, K. 1989. Influence of turbine clearance gap leakage on passage velocity and heat transfer near blade tips. I. Sink flow effects on blade pressure side. ASME Journal of Turbomachinery 111:284-292.

Moore, J., and Tilton, J. S. 1988. Tip leakage flow in a linear turbine cascade. ASME Journal of Turbomachinery 110:18-26.

Rued, K., and Metzger, D. E. 1989. Influence of turbine clearance gap leakage on passage velocity and heat transfer near blade tips. II. source flow effects on blade suction sides. ASME Journal of Turbomachinery 111:293-300.

Sjolander, S. A., and Amrud, K. K. 1987. Effects of tip clearance on blade loading in a planar cascade of turbine blades. ASME Journal of Turbomachinery 109:237-245.

Teng, S., Han, J.-C., and Azad, G. S. 2000. Detailed heat transfer coefficient distribution on a large-sacale gas turbine blade tip. Proceedings of ISROMAC-8, Honolulu, Hawaii, USA.

Wang, H. P., Goldstein, R. J., and Olson, S. J. 1999. Effect of high free-stream turbulence with large length scale on blade heat mass transfer. ASME Journal of Turbomachinery 121:217224.

Yamamoto, A. 1988. Interaction mechanisms between tip leakage flow and the passage vortex in a linear turbine rotor cascade. ASME Journal of Turbomachinery 110:329-338. 

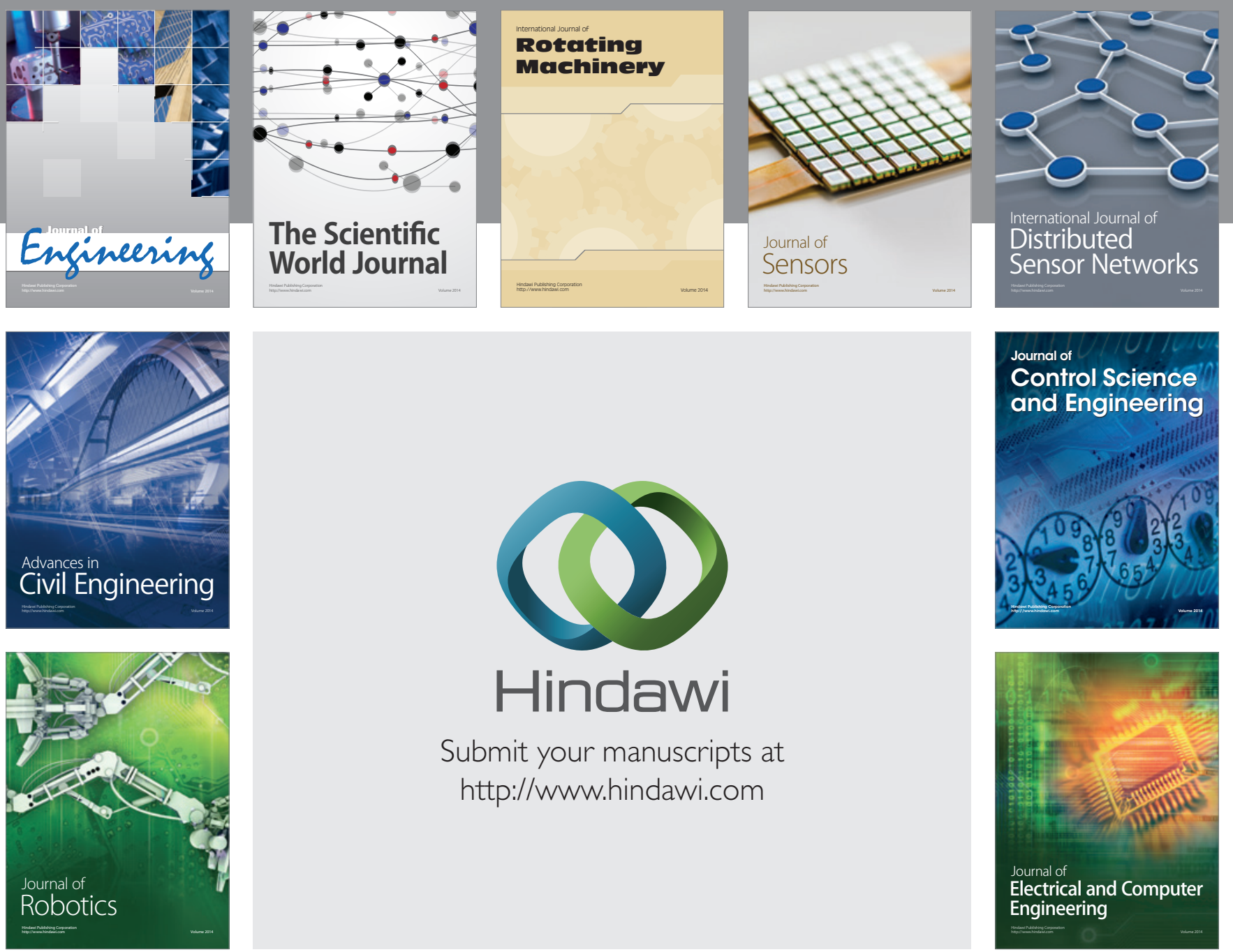

Submit your manuscripts at

http://www.hindawi.com
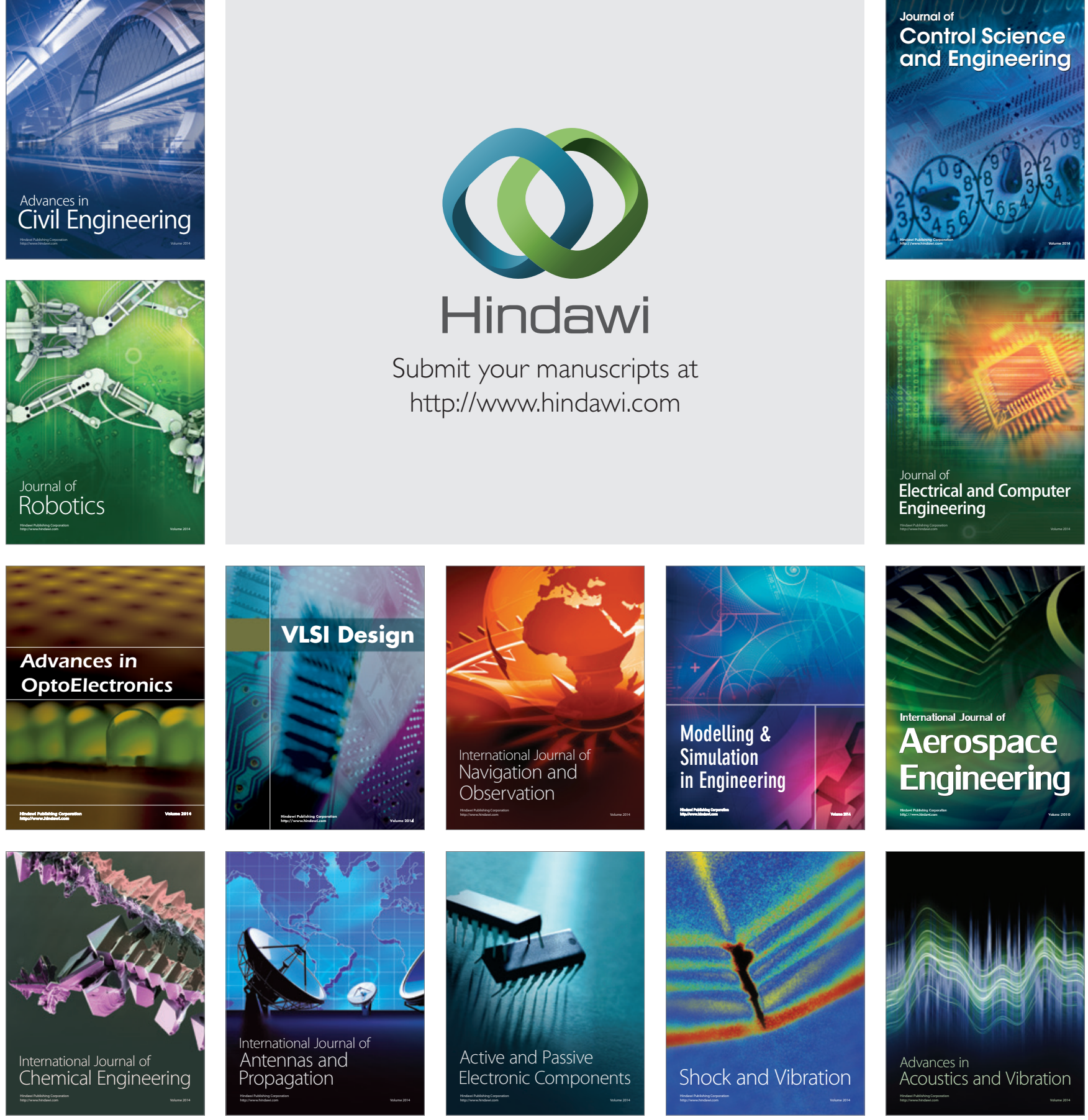